\title{
MULTIPLE OBJECTIVE LINEAR PROGRAMMING MODEL APPLIED TO SUSTAINABILITY
}

Zhi Tao, University of Alaska Anchorage, U.S.A.

Rebecca Abraham, Nova Southeastern University, U.S.A.

Ravi Chinta, Nova Southeastern University, U.S.A.

\section{dx.doi.org/10.18374/JABE-21-1.2}

\begin{abstract}
This research studies sustainability which is viewed from triple bottom line (TBL) perspective. Multiple objective linear programming (MOLP) model is applied to sustainability. We further narrow down to triple objective of minimization of production cost, carbon emission generated and life-threatening accidents associated with work for a business case and discuss the tradeoffs of TBL. The example of the business case and its solution shed light for other businesses to achieve and balance goals in sustainability.
\end{abstract}

Keywords: Sustainability, triple bottom line, multiple objective linear programming, goal programming, carbon emission, weight. 